\title{
Tackling Contemporary Challenges through Strengths based Approach in Social Work
}

\author{
Sebastin K V \\ School of Social Work, Roshni Nilaya, Mangalore, Karnataka, India \\ *Corresponding Author: sebshaila@gmail.com
}

\begin{abstract}
Social work practitioners work with problems of individuals and groups and organizations, where the demands often require finding sustainable and effective solutions. Practitioners may indulge in a variety of methodologies but the objective continues to remain solution focused. Most people who suffer from ailments often feel as if they are victims of situations and fail to look within their own resources for solutions. It is at this moment that we need to highlight people's strengths to derive a solution for their persisting problems. Deficits could thus be discounted to tackle by tackling the case through strengths based approach to explore more effective results. Strengths based practice is a social work practice theory that emphasizes people's strengths and self-determination. People are bestowed with innate capacity, skills, knowledge and other potential qualities which are often not tapped optimally during challenges. The challenges or struggles could well be addressed if the strengths highlighted. This paper analyses the significance of the Strengths Based Approach in Social Work and its relevance to the changing times. It is strongly believed that the evolution of this approach is in synthesis with the existing practices but a step forward towards effective problem solving on a case to case basis. When an individual realizes one's full potential and ability of doing things, it naturally enables them to have a more enriched life to make a better living for them.
\end{abstract}

Keywords Social Work, Strengths approach in social work, counselling

\section{Introduction}

Give $a$ man a fish and you feed him for a day; teach a man to fish and you feed him for life time...

Let us move beyond the conventional connotation of this anonymous Chinese proverb and think in the contemporary perspective of Social Work Practices. We can well evolve a corollary that the adage means that it is important not just sufficient to meet the immediate need of an individual but look at long term solution to the issue that needs to be tackled. This proverb very aptly distinguishes between the conventional practices of need based or deficit based approach and the strength based approach in social work practices.

In simple terms, the fish in question is the need or in other words the issue here is that of hunger. Giving fish might suffice the immediate need of the person but the act will only push him towards dependence in the long run. However, when the solution provider (Social Work Practitioner) thinks out of the box and identifies the strengths of the person and realizes that he can well be able to fish for himself, the act of teaching him to fish for his long term sustainability is the solution that is often desired. This is exactly the concept of Strength Based Approach in social work practices.

\section{Contemporary Social Work Practices}

The field of social work has evolved with the passage of time and has reached a threshold when there is high degree of efficacy required for the social work practitioners to achieve as the problems are quite demanding and the expectations with regard to the desired results are, so much more high. Social work practitioners today, work with individuals, groups or communities and organizations and there are problems galore.

The efficiency of the social work practitioner depends on the skill of addressing the problems faced in the most effective and sustainable manner. Quick time solutions or short term solution is no longer appreciated. Hence the challenge is to dig the issue deeper, understand the same thoroughly and then evolve long term solutions that are sustainable.

The conventional methodologies of redressing problems have encountered their own disadvantages and failed to achieve desirable results quite often. Hence the need was felt to deviate from the conventional approach which was more problem oriented to something that is more solution oriented. That is when the propagators of 'Strength Based Approach' came up with their theories of sustainable solutions to problems encountered by social work practitioners. 


\section{Strength Based Approach and its Evolution?}

Every individual, group or an organization is naturally bestowed with innate strengths. However, it is the weakness or the emptiness that is mostly visible and social work practitioners immediately latch on to it so as to evolve solution to the problems based on these negative attributes. It is then that the strengths do not come to fore. . This was a typical response to the deficit theory which speaks of tackling the pathology of the problem in hand for a desired solution. This has been a long standing practice in social work intervention so when desirable results were not forthcoming, practitioners had to think of other alternatives. The positive persona of an individual or a group was found to be a better means of tackling the problems

Ever since the emphasis on people's self-determination and strengths the concept of problem solving took a new dimension. Practitioners were convinced that deficit could thus be discounted to tackle the case through strengths based approach to explore more effective results.

The American social work tendency to adopt the Psychoanalytic approach with clients was strongly criticized by social workers of the likes of Bertha Reynolds, Dennis Saleebey, Charles Rapp and Anne Weick who developed their theories on the 'Strength Model'. The 1990s witnessed significant developments in this field of social work practice. It is pertinent to mention the observations of the president of the American Psychological Association in 1999, Dr. Martin Seligman, which fuelled strength-based practice: "The most important thing we learned was that psychology was half-baked. We've baked the part about mental illness, about repair damage. The other side's unbaked, the side of strength, the side of what we're good at" (Buckingham \& Marcus 2007).

The strength-based approach has been of late adapted and applied to many contexts, may it be in tackling individual or family issues, community development, service sector, labour or organizational issues. Numerous case studies practitioners and literature provide validation to the effectiveness of the strength based approach to social work practices. It is pertinent to mention that in no way, strengths-based approach denies the fact that people experience problems and challenges. It is only that these issues do need to be taken into consideration in a more holistic manner (Wayne Hammond, 2010).

The conventional approach based on deficit or problems often tends to limit options of deriving solutions as it includes Labelling. It tends to focus on "can'ts" as opposed to the "cans" thereby obscuring the recognition of a person's unique capabilities and strengths, Furthermore, the approach works on established templates or formats instead of individualizing solutions and ignores potential resulting from adversities.

Most problem solving approaches involves identification of what is wrong; this process involves analysing the causes, deciding on goals to fix these causes, making plans that will achieve the goals, implementing the plan and evaluating whether or not the problem was fixed. On the other hand, the strengths approach offers a genuine basis for addressing the primary mandate of community and mental health services people taking control of their own lives in meaningful and sustainable ways. It focuses on trusting and workable relationships, empowering people, working in collaborative ways on mutually agreed upon goals, drawing upon the personal resources of motivation and hope and finally creating sustainable change through learning and experiential growth.

\section{Problem Solving Approach Vs Strength Based Approach}

Theresa J Early and Linnea F Glen Maye (2000 ) in their article 'Valuing Families : Social Work Practice with Families from a Strengths Perspective', aptly highlight the critical differences between the conventional problem solving approach visa-vis the more practically evolved strength based approach. Whilst they focus on analysing the two approaches on issues concerning family matters it could be stated that these differences are also evident in other fields of social work practices as well. They list the differences between the two approaches on the basis of parameters such as Initial Contact, Goal Identification, Assessment, Intervention and Evaluation Bases. While in the practitioners of the first approach rely on initializing by identifying and defining the problem, in the latter, it is the vision and hopes of the client for the future, which is defined. It is imperative that in the process of identifying the problems, it is the social work practitioner and the client who get involved in the process of diagnosis; it is only the client who has the say when it comes to spelling the hopes for future (Early \& Glen Maye, 2000).

Right from the initializing stage to the evaluation, the problem based approach purely focuses on the client's solution to the problem and the facilitator's role in providing a feasible solution. The exercise ends with the evaluation where it is assed asked if the problem is solved or to what extent the problem is solved. However, on the other hand, the strength based approach works with a mutual consultation between the client and the social work practitioner with the goals being bound by the creativity of the two. The evaluation is also a continuous process with redefining of goals by the client from a subjectivist point of view. Thus, the strength based approach is more objective and the problem solving happens in a more sustained manner.

\section{Strength Brings Hybridism for the Good}

Pulla \& Woods (2014) in their article titled 'The resilient Chinese in Australia: Ethnicity, identity and 'Chineseness' explores the multigenerational ethnicity of Chinese people in Australia, particularly those who are long settled and 
Australian-born. The interesting essay discusses on how ethnicity could be maintained by a community in a land away from their own; not compromising on the development paradigm and regulations of the host society. The social scientists termed this development as Hybridist which has evolved through the innate strength of the community which has effective adapted to the changing times. The community which is subjected to discrimination on the basis of ethnicity has intricately chalked out ways in which they have coped with racism, utilizing ethnic and cultural coping, building their resilience to continue forward. The neo identity, not compromising on the roots or the evolution of Hybridism (Duel Identity) can only be developed by harnessing the innate strengths to sail over the situation.

\section{Strength Enables Deviation from the Beaten Path}

In addressing issues and/or concerns of a particular community, a social work practitioner often has to explore possibilities beyond a prescribed format or theory and work towards finding desirable and sustainable solutions. A small experiment in a tribal hamlet in Mudigere taluk of Chikmagalur District, Karnataka, India a few years ago can be cited as an example for how beaten paths can be avoided to achieve self-reliance and development.

Often, Self Help Groups (SHG) are inter-connected with financial transactions with a lending organization supporting the group of like-minded individuals who involve in multitude of activities for self-sustenance and growth of the community. Little does one realize that there are bound to be intricate issues when finances are involved and the interest rates to be paid back may well be a deterrent to the sustained interest levels of the members of the groups. Though there have been many success stories, there are disastrous tales as well.

The social work practitioner who was addressing the issues of this small hamlet comprising of about 20 families belonging to Asala community (Scheduled Tribe) residing in a remote village adjoining thick forest on one side and coffee estates on the other, thought otherwise and explored the opportunity to redefine the concept of SHG in his own way. He thought that money was a deficit attribute for the group and general SHG format tackles their problems through this very deficit of pathology. However, on working with the group, it was found that there were some salient features in the group that were their strengths with the cordial community living being their biggest. Another unrecognized strength was the availability of a crucial resource called land.

Instead of any financial investment, the social work practitioner chose to convince the group to part with a portion of each one's land and also join hands to put in their combined man power to work in the plot for cultivating any of the cash crops. The idea was readily agreed upon and the group earmarked an acre of land and also decided to work on the plot on a rotation basis once a week to cultivate Bananas which is a fast yielding fruit crop with appreciable revenue generation. The idea was enormously effective and soon the group was moving towards self-sufficiency and self-reliance, neither without a bank loan being availed nor to part with any amount in the form of interest on loans. Instead, they were soon working on creating a corpus from the revenue generated from the harvest (CORD Annual Report 2012).

\section{Building Family Values through Strength}

It is an absolute necessity that solutions are derived by building on family's strengths and intrinsic motivation rendered to meet the needs and reach the goals. The family goals generally are a combination of the individual goals of the head of the family and that of the common good. The social work practitioner has to realize these minute aspects while getting into consultation with the client. It all begins with the conversation between the two wherein the practitioner asks 'door-opening' questions which has the capacity to clear the air and provide more details for further analysis of the final goal (Early \& GlenMaye 2000).

There can be a wide spectrum other turbulent situations that can often dislodge the functioning of this first social unit called 'family' These can range from violent outbursts by a young son, woes of single parenting, a pampered daughter of a busy employed couple, a drunkard father in constant violent act against the lady of the house, rising expectations of siblings due to peer pressure. The challenge for the social work practitioner is not just about identifying the problem and rendering immediate solutions but to study in-depth the cause and effects of the problems, identify the reasons behind such a situation and provide a sustained solution. It is often observed that each of the members of a family have their own innate strengths which has been submerged in the 'flooding waters' of the prevalent problems. It is only these subdued strengths that have the long term solution to the problems and which may look very superficial when solved.

\section{Strength Approach Grooms Individuals}

Children growing up in different environment are subjected to different exposure and experiences and hence have different levels of understanding, priorities, confidence and attitudes which can create difficulties when brought under the one roof. For example; a city based child may have been exposed to a life of comfort and high standard of living as compared to a child growing up in a village, especially in a typically Indian context.. Often, children coming from diverse backgrounds may not be able to gel well among each other when put together. The case is even difficult when a child comes from a under privileged section both in terms of societal norms and economic criteria. For example; the child 
is bound to suffer from acute lack of self-confidence and low self-esteem. This surely poses a challenge for a social work practitioner working with such target groups.

The problem based approach to problem solving may actually aggravate the problem instead of deriving a solution or the desired change in individuals. An experiment to bring together a group of sixty children and working with them on helping identifying their talent and skills, in other words their strengths, worked appreciably well in grooming them as more confident individuals.

A group of children belonging to Koraga Community (Primitive Tribe in Dakshina Kannada District, Karnataka, India) from different parts of the district were brought together for twenty days with the main focus being on increasing self-esteem. This program was under the patronage of the local administration (Zilla Panchayat). The children, back home lacked basic amenities which are enjoyed by the other villagers or the city dwellers. Some of them even had no supply of electricity to their dwellings. The challenge in front of the social work practitioners was rather huge (CIL, Report 2014). They chose not to highlight the problems of the children which made them seemingly lack self-confidence The resource group that worked with these children (aged between 12 and 16 years) first identified the innate skills among them. It was noticed that though they were averse to the idea of coming forward and speaking, they were found to be extremely creative and worked well in groups without much formal direction. This strength was zeroed in and the resource group worked out a plan to bring their strengths to the fore so as to build their confidence. The exercise to make them aware of their positives (which no one had helped them identify), enthused them to learn new subjects with ease. Teaching Spoken English to children who would shy away from even standing in front of someone who knows half of this foreign language, surely was an herculean task to begin with. But, the support system, provided by identifying their strengths in the form of creativity and talent, enabled them to open up and try to improve their English Speaking Skills. The interesting part of the experiment was that in view of teaching spoken English, the language was used by the resource group in a subtle manner while giving instructions at the dining area or any other activity that the children were undergoing. The desired result e even a short period of time was definitely achieved as the change in mind-set was evident. Sustained improvement in these children can be achieved in two ways; by further focusing on their progress (whatever little); and, by not intensifying the course curriculum but rather the more informal approach of teaching English during everyday activities and play.

We now realize that the strength based approach in social work practices is in fact constructive reaction to the rather conservative and conservative approach based on problem solving. In its most practical and pragmatic sense, the strength-based approach enhances strengths, building on characteristics that are already present in individuals. Thus the solutions to any problem is originates from within oneself and the social work practitioner is a mere facilitator.

It is also evident that there can be no prescribed format for tackling a problem of any kind and that even visibly similar problem may have different approaches to deal with as the individuals in each case will be differently bestowed with their unique strengths.

According to Powell, \& Batsche, (1997), a strength-based philosophy is a critical belief; an all-pervasive attitude that informs a professional's interactions with clients. Ideally, an entire agency will adopt the approach, and, through ongoing training, this attitude-change will occur in all staff, transforming the way they view their work, their colleagues, and, subsequently, the people and communities they work with.

Strengths in an individual, group or an organization will generate the resources to tackle the problem and the social work practitioner has to play the role of a facilitator to identify the skills, interests and support systems that enable desirable results.

There is little doubt that there is need for more research and further evaluations of the strength-based approach as specifics of qualitative and quantitative efficacy of the evaluations are yet to be accurately projected. However, the paradigm shift in visualizing a problem by the social work practitioner could well bear a positive impact on the process of treatment and rehabilitation of the subject under the scanner (Krabbenborg, Boersma, , \& Wolf,.,2013) and (Barwick,. 2004).

An Illustration of a Strength Based approach in a Family by (Early and GlenMaye 2000) highlights the issues relating to Single parenting; often a matter of concern for social work practitioners who need to render special attention to their clients. The stress and anxiety levels of such individuals are a challenge to the facilitator who has to strategize each move to bring the affected out of the trauma in the most holistic manner. They explain in detail a case which involved a hyper active son with his mother who had sacrificed her prime for his upbringing. The emotional outbursts, especially those manifesting violence of the son as he grew, become a serious matter of concern for the two-member family. The outbursts began to increase as the boy turned ten years old, described as being unbearable and difficult for the single mother to manage. She too would react undesirably at times due to the increasing stress level. Accessing a child helpline and rehabilitation centre, they became involved working with a proficient social work practitioner who adopted techniques which focused on their strengths thereby transforming their lives. Interestingly, the problem of the boy and the miseries of the mother were totally discounted by the social worker who focused on their innate strengths and inclinations. The boy had a flair and interest for drawing and visual arts while the mother was a trained nurse. Given that this almost 15 years ago, she felt that it was of no use as she was not licensed and thus not recognizing the skills and knowledge she already possessed. These attributes of the two became the focus instead for the professional to provide alternative forms of expression for the young boy and also empower his 
mother to cope with the emerging situation.

\section{Conclusion}

Some of the principles developed by social scientists, researchers and practitioners over the period, have served as the foundation for guiding and implementing strength-based practice (Wayne Hammond, 2010).Evidently, it is thus established that every person has potential and it is their unique strengths and capabilities that will determine their evolving story as well as define who they are - not their limitations. Strength based practitioners, focus, not on labels, but an individual's reality, whilst drawing out strengths, and thus creating hope and optimism. Furthermore, the language used creates our reality - both for the care providers and the children, youth and their families. It is the change that is ultimately intended and not about the reduction of problems. Adopting the strength based approach stresses on the thought that all individuals have the urge to succeed, to explore the world around them and to make them useful to others and their communities. It is all about building one's capacity not just to overcome the problem at a particular juncture but develop confidence to deal with any situation arising in future as well. Though the approach to practice is not entirely new, it needs more refinement and more research to be undertaken.

With the elaboration of various aspects of societal issues and the approach required, it surely is convincing that Strengths Based Approach in Social Work has a great sense of relevance in the changing times. It could be strongly stated that the evolution of this approach is in synthesis with the existing practices but a step forward towards effective problem solving on a case to case basis. When an individual realizes one's full potential and ability of doing things, it naturally enables to have a more enriched life.

The same old Chinese adage lingers in the mind that we need to build capacity of an individual through his or her innate strengths (teaching to fish), rather than to give instant solutions based on the problems of the moment (Giving a fish). We can thus conclude that 'viewing one's strengths strengthens individuals and groups'.

\section{REFERENCES}

Barwick, H. (2004). Young Males: Strength-based and Male-focused Approaches, A Review of the Research and Best Evidence. New Zealand: Ministry of Youth Development.

Buckinghum and Marcus, (2007). Put Your Strengths to Work: 6 Powerful Steps to Achieve Outstanding Performance. American Psychologist Annual Report, pp.559-562

CORD (2012). Annual Report of Coorg Organisation for Rural Development, Madikeri, Karnataka,India.

CIL (2014). Centre for Integrated Learning, Mangalore, Karnataka - Report of Camp for Koraga Children from October 2 to October 20, 2014 held at Madhya, Dakshina Kannada, Karnataka, India.

Early, T. J., \& GlenMaye, L. F. (2004). Valuing Families: Social Work Practice with Families from a Strengths Perspective. Social Work, 45(2), 118-130.

Wayne Hammond, Ph.D. (2010). Principles of Strength-Based Practice published by Resiliency Initiatives (P. 2-4).

Pulla,V, \& Jennifer Woods (2014) : The resilient Chinese in Australia: Ethnicity, identity and 'Chineseness', International Sociology, vol. 29, no. 5 Pp 388-395.

Powell, D. S. \& Batsche, C. J. (1997). A strength-based approach in support of multi-risk families: Principles and issues. Topics in Early Childhood Special Education, Pp 17, 1.

Krabbenborg, M. A., Boersma, S., \& Wolf, J. R. (2013). A Strengths based method for homeless youth: Effectiveness and fidelity of Houvast. BMC Public Health, Pp 13, 359-369.

Wayne Hammond, Ph.D. (2010). Principles of Strength-Based Practice, published by Resiliency Initiatives. Pp. 5. 